\title{
TINJAUAN TEOLOGIS PENGAJARAN PERSEPULUHAN TERHADAP PEMBERIAN PERSEMBAHAN PERSEPULUHAN DI GKII JEMAAT TAMALANREA MAKASSAR
}

\author{
Marlon Sumampouw, Robi Panggarra
}

\begin{abstract}
Abstrak
Tujuan dari penulisan ini adalah untuk menjelaskan tentang pengajaran teologis persepuluhan baik dari segi alkitabiah, pandangan dari ahli teologi, maupun aturan Gereja Kemah Injil Indonesia yang tertuang dalam Anggaran Dasar dan Anggaran Rumah Tangga terhadap ketaatan jemaat dalam mengembalikan persepuluhan di Gereja Kemah Injil Indonesia Jemaat Tamalanrea Makassar. Adapun metode penulisan yang digunakan oleh penulis adalah menggunakan metode penelitian kualitatif dengan teknik pengumpulan data berupa observasi, tinjauan pustaka, dan wawancara. Berdasarkan dari hasil penelitian maka penulis dapat menarik kesimpulan sebagai berikut: Pertama, tindakan jemaat dalam memberi persepuluhan adalah sebagai bentuk kesetiaan dan ketaatan terhadap perintah Tuhan dan sebagai dukungan terhadap pekerjaan Tuhan dalam organisasi GKII secara umum dan gereja lokal Tamalanrea Makassar secara khusus. Kedua, ketaatan jemaat dalam mengembalikan persepuluhan sangat berdampak pada kemajuan pelayanan utamanya dalam bidang penginjilan. Ketiga, jemaat yang setia dalam mengembalikan persepuluhan akan diberkati bukan cuma jasmani tetapi rohani. Tuhan senang ketika jemaat setia dan taat mendengarkan perintah Tuhan. Keempat, sikap dalam mengembalikan persepuluhan adalah yang utama di hadapan Tuhan. Kejujuran menjadi kunci utama ketika jemaat taat untuk mengembalikan persepuluhan. Kelima, memberi persepuluhan mengajar jemaat Tuhan untuk tidak terikat pada sikap materialisme dan hedonisme, namun sebaliknya jemaat Tuhan diajar untuk saling berbagi kepada sesama dan terus mendukung pekerjaan Tuhan lewat harta yang Tuhan percayakan kepada setiap jemaat Tamalanrea. Persepuluhan adalah sebuah kewajiban bagi orang percaya dalam mentaati perintah Tuhan, tetapi kewajiban itu juga harus disertai dengan rasa syukur, keikhlasan, dan sukacita karena itu yang berkenan di hadapan Tuhan.
\end{abstract}

Kata-kata kunci: Persepuluhan, Pengajaran, GKII, Jemaat, Tamalanrea, Kewajiban.

\section{Pendahuluan}

\section{Latar Belakang Masalah}

Pengelolaan keuangan yang baik adalah salah satu bukti bagi orang percaya dalam menjaga berkat yang Tuhan telah percayakan di dalam kehidupannya. ${ }^{1}$ Oleh karena itu

\footnotetext{
${ }^{1}$ Ardo Ryan Dwitanto, "Perpuluhan: Awal Pengelolaan Keuangan Pribadi Manajemen Kita," Tabloid Reformata Edisi 111, tahun VII (2009), 7. diakses 22 Februari 2019,
} 
perlu disadari bahwa seluruh aspek kehidupan orang percaya berada di bawah otoritas Kristus termasuk dalam hal pengelolaan setiap berkat harta yang dipercayakan Tuhan kepadanya. $^{2}$ Salah satu pengakuan orang percaya terhadap Tuhan adalah dengan memberikan persembahan kepada-Nya, dan menghormati Dia dengan harta benda yang sudah Tuhan percayakan, maka itu akan menolong setiap orang percaya dalam menilai dan memperlakukan setiap harta benda termasuk uang yang ada pada diri setiap orang percaya.

Jika berbicara tentang memuliakan Tuhan dengan harta atau uang tentu tidak lepas dari kata persembahan. Secara umum setiap orang yang datang untuk beribadah ke gereja pasti akan membawa persembahan yang nantinya akan berguna bagi pekerjaan dan pelayanan serta operasional gereja tersebut, walaupun pemberian persembahan bersifat wajib namun jumlah dari harta atau uang yang ingin diberikan untuk persembahan tidak diatur secara khusus dalam sebuah organisasi gereja. ${ }^{3}$ Hal ini pun penulis alami selama menjadi warga jemaat dan sudah menjadi kebiasaan umum dalam praktik peribadatan khususnya ruang lingkup gereja di Indonesia, orang-orang membawa uang untuk memberikan persembahan di gereja. Dengan kata lain persembahan umumnya sangat identik dengan uang.

Berbicara tentang persembahan tentu tidak lepas dari salah satu bentuk persembahan yang ada di dalam gereja saat ini yaitu, persepuluhan. Persepuluhan bukan menjadi hal yang baru dalam kehidupan warga jemaat gereja saat ini. Dalam Alkitab praktik ini telah dikenal dan dilakukan oleh Abram yang memberikan perpuluhan secara sukarela ${ }^{4}$ kepada raja Melkisedek karena Abram berhasil dalam peperangan (Kejadian 14: 17-20). Setelah kisah Abram kemudian disusul oleh cerita Yakub di Betel yang berjanji akan memberikan sepersepuluh dari apa yang diberikan oleh Tuhan kepadanya (Kejadian 28: 20-22) sampai akhirnya perpuluhan itu menjadi sebuah kewajiban bagi bangsa Israel dalam hukum Taurat pada zaman Musa, ${ }^{5}$ dengan tujuan bahwa persepuluhan itu dipakai oleh suku Lewi untuk mencukupi kebutuhan mereka, hal ini dikarenakan mereka tidak termasuk dalam suku Israel yang mendapat hak waris tanah Kanaan. Persembahan persepuluhan itu bukan hanya untuk orang Lewi saja melainkan juga digunakan untuk menghidupi orang miskin, anak yatim dan orang asing yang ada disekitar bangsa Israel. ${ }^{6}$

Pemahaman dan pengajaran tentang persepuluhan dalam Perjanjian Lama cukup jelas bahkan sistematis serta dipahami oleh pelakunya, namun hal ini bertolak belakang dengan pemahaman persepuluhan dalam jaman sekarang yang seringkali menimbulkan banyak pertanyaan. Ada satu pertanyaan yang kadang atau bahkan sering muncul dalam forum diskusi mengenai persepuluhan, yaitu ke mana seharusnya persepuluhan diserahkan? Pengajaran umum yang dipahami oleh orang percaya adalah persepuluhan harus dibawa ke Rumah Tuhan. ${ }^{7}$ Hal ini tentunya tidak salah jika bertolak dari kitab Maleakhi 3: 10. Namun dalam Perjanjian Baru tidak lagi mengatur dengan jelas tentang

https://books.google.co.id/books?id=E_ejBwAAQBAJ\&pg=PA14\&source=gbs_toc_r\&cad=3\#v=onepage\&q $\& \mathrm{f}=$ false.

${ }^{2}$ Murni H. Sitanggang, “Teologi Biblika mengenai Perpuluhan,” Veritas 12, no. 1 (2011): 19.

${ }^{3}$ Samuel Hutabarat, Memuliakan Tuhan Dengan Harta: Mengelola Berkat Financial Sesuai Standar Firman Tuhan (Yogyakarta: ANDI, 2014), 151.

${ }^{4} Y a m o w a ' a ~ B a t e ' e$, Mengungkap Misteri Persepuluhan: Praktik Persepuluhan Dilakukan Tetapi Tidak Dimengerti (Yogyakarta: ANDI, 2013), 47.

${ }^{5}$ Steven Teo, Persepuluhan Kunci Kebebasan Finansial: Menguji Tuhan Dengan 10\% Income Kita (Yogyakarta: ANDI, 2013), 5-6.

${ }^{6}$ Josef P. Widyatmadja, Yesus Dan Wong Cilik (Jakarta: BPK Gunung Mulia, 2010), 23.

${ }^{7}$ Benry Pandiangan dan Stimson Hutagalung, “Analisis Pemahaman Anggota Jemaat Pakusarakan Tentang Mengembalikan Persembahan Persepuluhan Ke Rumah Perbendaharaan Tuhan Menurut Maleakhi 3:10," Jurnal Marturia 1, no. 1 (1 Juli 2017): 117. 
persembahan persepuluhan seperti Perjanjian Lama sehingga sedikit banyak menimbulkan kebingungan di antara orang percaya. Selain itu pertanyaan lain yang juga sering ditanyakan adalah apakah persepuluhan harus $10 \%$ ? Apakah tidak boleh kurang atau lebih?

Dalam hal pengajaran persembahan persepuluhan, beberapa denominasi gereja di Indonesia ada yang mendukung praktik ini tetapi tidak sedikit pula gereja yang menolaknya, bahkan dalam jemaat lokal dalam suatu denominasi gereja terkadang juga saling bertentangan mengenai persepuluhan ini. Gereja yang mendukung praktik ini sangat menekankan betapa pentingnya jemaat untuk taat dan setia dalam hal memberi

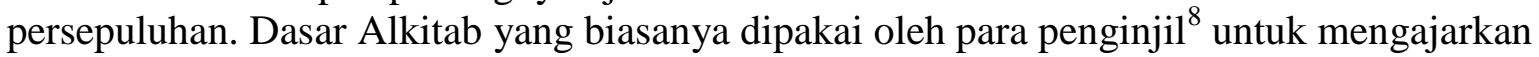
jemaat dalam memberi persepuluhan terambil dari kitab Maleakhi 3: 10 "Bawalah seluruh persembahan persepuluhan itu ke dalam rumah perbendaharaan supaya ada makanan di rumah-Ku. Ujilah Aku," firman TUHAN semesta alam, "apakah Aku tidak membukakan tingkap-tingkap langit untukmu dan mencurahkan berkat kepadamu sampai berkelimpahan." Persepuluhan adalah kunci untuk membuka pintu berkat Tuhan dalam kehidupan setiap manusia. ${ }^{9}$ Mills mengatakan "Jangan terkejut dengan kemiskinan di dalam kehidupan anda jika anda tidak mengembalikan persepuluhan."10 Oleh karena itu seharusnya setiap jemaat Tuhan yang taat dan setia dalam memberikan persepuluhan pasti diberkati karena inilah yang menjadi janji Tuhan kepada setiap umat-Nya. Bright menegaskan bahwa memberikan persepuluhan akan memerdekakan setiap orang percaya dari tirani materialisme dan memperlancar saluran berkat Allah yang melimpah itu. ${ }^{11}$ Agustina dan Irianto menjelaskan bahwa "ada sebuah konsekuensi yang positif bagi manusia jika doktrin dari Allah ini ditaati oleh manusia" konsekuensi positif itu berupa kelancaran atau kesuksesan dalam menjalani kehidupan di mana orang percaya tidak akan kekurangan karena ini merupakan janji Tuhan. ${ }^{12}$

Jadi, pada hakikatnya orang yang taat dan setia mengembalikan milik Tuhan dalam bentuk persepuluhan akan diberkati karena ini janji Tuhan dan sekaligus sebagai alat pembelajaran agar manusia tidak terikat pada materialisme. Lewat persepuluhan manusia diajarkan bahwa apa yang ada padanya semuanya adalah milik Tuhan. Selain itu banyak hal yang gereja dapat lakukan dalam pelayanan jika jemaat taat dalam mengembalikan persepuluhan. Salah satu gereja yang melakukan praktik persepuluhan yaitu Gereja Kemah Injil Indonesia Jemaat Tamalanrea Makassar.

Gereja Kemah Injil Indonesia Jemaat Tamalanrea Makassar terdiri dari berbagai suku, strata sosial, dan latar belakang pendidikan yang berbeda-beda. ${ }^{13}$ Sistem persepuluhan telah diatur dalam aturan baku Gereja Kemah Injil Indonesia begitupun dengan sistem pengelolaannya. Setiap anggota jemaat yang telah terdaftar dalam lingkungan gereja lokal Kemah Injil Indonesia maka wajib dan setia untuk membawa persepuluhannya secara rutin ke dalam perbendaharaan gereja. Jika dilihat dari beberapa pemahaman dan aturan gereja, seharusnya jemaat yang telah mendapat pengajaran dan telah terdaftar sebagai jemaat maka wajib untuk memberikan persepuluhannya. Namun

\footnotetext{
${ }^{8}$ Herlianto, Teologi Sukses Antara Allah Dan Mammon (Jakarta: BPK Gunung Mulia, 2009), 189.

${ }^{9}$ Stanley et al., "Pengaruh Persepuluhan Terhadap Pertumbuhan Kesejahteraan Jemaat Di Gereja Bethany Indonesia ‘Almasih Qom' Surabaya,” Jurnal Kerusso 3, no. 1 (28 Maret 2018): 23.

${ }^{10}$ Dag Heward Milss, Mengapa Orang-orang Kristen Yang Tidak Mengembalikan Perpuluhan Menjadi Miskin Dan Bagaimana Orang-Orang Kristen Yang Mengembalikan Perpuluhan Menjadi Kaya (London: Parchment House, 2015), 6.

${ }^{11}$ Bill Bright, Memberi Dengan Sukacita (Jakarta: LPMI, 2001), 151.

${ }^{12}$ Agustina Christina Patty dan Gugus Irianto, “Akuntabilitas Perpuluhan Gereja,” Jurnal Akuntansi Multiparadigma 4, no. 2 (2013): 178.

${ }^{13}$ Terdapat tantangan pandangan yang berbeda-beda. Objantoro, 56.
} 
pada kenyataannya masih ada jemaat yang belum setia memberikan persepuluhannya kepada gereja.

Selain itu, jika mengacu pada janji Tuhan maka jemaat yang setia dan taat dalam memberikan persembahan persepuluhan akan diberkati baik itu secara jasmani dan rohani. Namun pada kenyataannya masih ada jemaat yang hidup dalam kekurangan. Jika berpedoman pada janji Tuhan berarti kemungkinan besar jemaat yang masih hidup dalam kekurangan tidak setia dalam mengembalikan persepuluhan sehingga mereka tidak diberkati Tuhan. Kemungkinan juga mereka setia mengembalikan persepuluhan tetapi tidak dilakukan dengan sikap yang benar di hadapan Tuhan.

Oleh karena itu berdasarkan latar belakang masalah di atas, maka penulis tertarik untuk meneliti dan menulis skripsi dengan judul: TINJAUAN TEOLOGIS PENGAJARAN PERSEPULUHAN TERHADAP PEMBERIAN PERSEMBAHAN PERSEPULUHAN DI GKII JEMAAT TAMALANREA MAKASSAR.

\section{Pokok Masalah}

Berdasarkan latar belakang masalah di atas maka, rumusan pokok masalah yang akan dibahas dalam penulisan skripsi ini adalah:

Pertama, apakah sebenarnya yang dimaksud dengan persembahan persepuluhan? bulan?

Kedua, apakah jemaat taat dan setia dalam mengembalikan persepuluhan setiap

\section{Tujuan Penelitian}

Adapun yang menjadi tujuan dari penulisan skripsi ini adalah:

Pertama, untuk mengetahui apa sebenarnya yang dimaksud dengan persembahan persepuluhan.

Kedua, untuk mengetahui sejauh mana ketaatan dan kesetiaan jemaat dalam mengembalikan persepuluhan secara sistematis.

\section{Manfaat Penelitian}

Adapun manfaat penulisan yang ingin dicapai melalui penulisan skripsi ini adalah sebagai berikut:

Pertama, tulisan skripsi ini diharapkan dapat menjadi bahan bacaan yang dapat menambah wawasan bagi orang percaya pada umumnya dan terkhusus bagi mahasiswa teologi serta hamba-hamba Tuhan sebagai bahan rujukan mengenai prinsip persepuluhan.

Kedua, agar dapat menjadi pedoman yang baik tentang persepuluhan, bukan hanya secara konseptual namun juga dapat diimplementasikan dalam kehidupan kekristenan secara umum dan jemaat Gereja Kemah Injil Indonesia Jemaat Tamalanrea Makassar secara khusus.

Ketiga, untuk memenuhi salah satu syarat akademik dalam mencapai gelar sarjana (S-1) pada Sekolah Tinggi Filsafat Jaffray Makassar. 


\section{Metode Penelitian}

Metode penelitian yang digunakan oleh penulis dalam penulisan skripsi ini adalah menggunakan metode penelitian kualitatif dengan teknik pengumpulan data yaitu, berupa tinjauan pustaka, observasi lapangan dan wawancara. ${ }^{14}$

Pertama, tinjauan pustaka, menggunakan metode penelitian kepustakaan, di mana penelitian dilakukan lewat buku-buku, jurnal-jurnal yang berhubungan dengan pengajaran persepuluhan dan pandangan-pandangan dari para ahli teolog mengenai persepuluhan. Selain itu tentu yang menjadi sumber utama dalam penelitian kepustakaan ini adalah Alkitab sebagai tuntunan dan rujukan dalam mengerti dan memahami tentang persepuluhan.

Kedua, observasi lapangan, Observasi adalah pengamatan yang melibatkan pencatatan secara sistematis dan etis terhadap hal apa yang teramati di lapangan. ${ }^{15}$ Oleh karena itu observasi atau pengamatan yang penulis lakukan di GKII Jemaat Tamalanrea Makassar adalah mengamati hasil laporan keuangan yang diterbitkan setiap bulan yang terpasang pada dinding informasi gereja, dan mengamati laporan keuangan yang diterbitkan lewat buletin setiap minggu.

Ketiga, wawancara, teknik wawancara dilakukan oleh dua orang dalam sebuah pertemuan dimana pertukaran informasi dan ide terjadi melalui tanya jawab. ${ }^{16}$ Berdasarkan dari pengertian tersebut penulis akan melakukan wawancara kepada beberapa sampel untuk memperoleh informasi sejauh mana pemahaman mereka terhadap persembahan persepuluhan, apakah mereka memberikan persepuluhan secara sistematis atau tidak, dan sekaligus mengetahui apakah ada peningkatan ekonomi ketika mereka taat mengembalikan persepuluhan.

Keempat, hasil dari wawancara dan observasi lapangan mengenai pengajaran persembahan persepuluhan di GKII Jemaat Tamalanrea Makassar akan dianalisis dengan cara menjelaskan dan menyimpulkan dalam bentuk uraian.

\section{Batasan Penelitian}

Mengingat begitu luasnya pemikiran dan pengajaran tentang teologi persepuluhan, maka dalam skripsi ini penulis akan membatasi pembahasan dengan penelitian dilakukan di Gereja Kemah Injil Indonesia Jemaat Tamalanrea Makassar. Apabila terdapat kutipan ayat-ayat dari Alkitab atau kitab-kitab lainnya dalam Alkitab Perjanjian Lama maupun Perjanjian Baru serta buku-buku yang ditulis oleh pakar teologi sehubungan tentang persepuluhan, itu hanya merupakan referensi perbandingan.

\section{Sistematika Penulisan}

Untuk memudahkan pemahaman pembaca, penulis menguraikan sistematika dari penulisan skripsi ini sebagai berikut:

Bab 1, merupakan pendahuluan yang berisikan latar belakang masalah, pokok masalah, tujuan penelitian, manfaat penelitian, metode penelitian, batasan penelitian, dan sistematika penulisan.

\footnotetext{
${ }^{14}$ Hasmawaty, 55; Rantesalu, 43.

${ }^{15}$ Christine Daymon dan Immy Holloway, Metode-Metode Riset Kualitatif Dalam Public Relation Dan Merketing Communication (Yogyakarta: Bentang Pustaka, 2008), 319.

${ }^{16}$ Hengky Wijaya, Metodologi Penelitian (Makassar: Sekolah Tinggi Theologia Jaffray, 2016), 70.
} 
Bab II, tinjauan pustaka yang meliputi definisi dan pengertian persepuluhan, dasar persepuluhan dalam PL dan PB, pandangan para teolog mengenai persepuluhan serta aturan atau pandangan Gereja Kemah Injil Indonesia mengenai persepuluhan.

Bab III, analisis hasil lapangan terdiri dari sejarah singkat tempat penelitian, analisis dan pembahasan hasil lapangan tentang pengajaran persepuluhan dalam jemaat Tamalanrea Makassar, serta alokasi dana persepuluhan jemaat.

Bab IV, tinjauan teologis pengajaran persepuluhan terhadap persembahan persepuluhan Gereja Kemah Injil Indonesia Jemaat Tamalanrea

Bab V, merupakan kesimpulan dan saran-saran.

\section{Kesimpulan}

Berdasarkan dari hasil tinjauan teologis pengajaran persepuluhan terhadap pemberian persembahan persepuluhan di GKII Jemaat Tamalanrea Makassar maka dapat ditarik kesimpulan sebagai berikut:

Pertama, tindakan dalam memberi persepuluhan bagi Jemaat Tamalanrea adalah bentuk kesetiaan dan ketaatan terhadap perintah Tuhan dan sebagai dukungan terhadap perkerjaan Tuhan dalam organisasi GKII secara umum dan gereja lokal Tamalanrea Makassar secara khusus.

Kedua, ketaatan jemaat dalam mengembalikan persepuluhan sangat berdampak bagi kemajuan pelayanan utamanya dalam bidang penginjilan, walaupun belum semua jemaat memberikan persepuluhannya, namun dari praktik ini terbukti dengan banyaknya pos PI yang dibuka oleh jemaat Tamalanrea Makassar beberapa diataranya telah menjadi jemaat mandiri, ada yang diserahkan kepada gereja lain dalam lingkungan GKII untuk menjadi pos PI binaan gereja tersebut, dan ada yang masih dibina sampai sekarang oleh jemaat Tamalanrea Makassar.

Ketiga, jemaat yang setia dan taat dalam memberikan persepuluhan diberkati baik secara jasmani dan rohani, namun bukan karena banyaknya nominal pemberian atau karena persepuluhannya yang membuat jemaat diberkati tetapi karena ketaatan dan kesetiaan jemaat melakukan perintah Tuhan yang membuat berkat mengalir dalam hidup mereka.

Keempat, prinsip jujur di hadapan Tuhan adalah dasar utama bagi jemaat dalam memberikan persembahan persepuluhan, jika Tuhan memberkati lebih maka secara otomatis persepuluhan kita juga besar, namun sebaliknya jika berkat yang diterima kecil maka nominal yang diberikan juga kecil. Berilah sesuai dengan apa yang diperoleh oleh masing-masing jemaat

Kelima, memberi persepuluhan mengajar jemaat Tuhan untuk tidak terikat pada sikap materialisme dan hedonisme, namun sebaliknya jemaat Tuhan diajar untuk saling berbagi kepada sesama dan terus mendukung pekerjaan Tuhan lewat harta yang Tuhan percayakan kepada setiap jemaat Tamalanrea.

\section{Saran-saran}

Adapun saran-saran yang penulis dapat berikan kepada jemaat Tamalanrea Makassar mengenai hasil dari seluruh uraian dalam karya penulisan ini adalah sebagai berikut:

Pertama, persepuluhan adalah sebuah sistem ekonomi yang dibangun untuk mendukung keperluan pelayanan dan pekerjaan Tuhan. Oleh karena itu disarankan buat jemaat yang belum memberikan persepuluhan agar mulai belajar untuk setia dalam membantu pekerjaan Tuhan lewat pemberian persepuluhan. 
Kedua, disarankan kepada gembala jemaat, para hamba-hamba Tuhan, dan BPJ untuk senantiasa memberikan pengajaran yang benar serta sesuai dengan Firman Tuhan mengenai persembahan persepuluhan kepada jemaat agar jemaat memahami dan mempraktekkannya dalam kehidupan berjemaat.

Ketiga, kepada jemaat yang telah setia membawa persepuluhannya ke rumah Tuhan agar terus melakukannya dan disertai dengan motivasi yang benar di hadapan Tuhan.

\section{Kepustakaan}

Achenbach, Reinhard. Kamus Ibrani-Indonesia. Jakarta: Yayasan Komunikasi Bina Kasih, 2012.

Alaka, Samuel. The Power \& Mystery Of Tithing. Nairobi Kenya: Bethel Publishers, 2010. Allis, Oswald T. Tafsiran Alkitab Masa Kini Jilid 1 Kejadian - Ester. Jakarta: Yayasan Komunikasi Bina Kasih, 2012.

Alkitab Terjemahan Baru. Jakarta: Lembaga Alkitab Indonesia, 2015.

Anggaran Dasar Dan Anggaran Rumah Tangga Gereja Kemah Injil Indonesia

Amandemen Tahun 2016 Nomor 1. Jakarta: Gereja Kemah Injil Indonesia, 2016.

Badudu, J. S. Kamus Kata-Kata Serapan Asing Dalam Bahasa Indonesia. Jakarta: PT. Kompas Media Nusantara, 2007.

Barker, Paul. Kitab Ulangan: Allah Yang Menepati Janji-Janji-Nya. Jakarta: Literatur Perkantas, 2014.

Bate'e, Yamowa'a. Mengungkap Misteri Persepuluhan: Praktik Persepuluhan Dilakukan Tetapi Tidak Dimengerti. Yogyakarta: ANDI, 2013.

Bayo, Chosen. Tithes? The Truth about Tithes, Offerings, and Free Will Giving. New Jersey, Pennsauken: BookBaby Publisher, 2016.

Bright, Bill. Memberi Dengan Sukacita. Jakarta: LPMI, 2001.

Brill, J. Wesley. Dasar Yang Teguh. Bandung: Yayasan Kalam Hidup, 1994.

Brott, Rich. A Biblical Perspective on Tithing \& Giving: A Believer's Stewardship Guide. Florida: ABC Book Publishing, 2008.

Browning, W. R. F. Kamus Alkitab: A Dictionary of the Bible. Jakarta: BPK Gunung Mulia, 2016.

Budiselic, Erwin. "The Role and the Place of Tithing in the Context of Christian Giving."

Kairos - Evangelical Journal of Theology 8, no. 2 (2014): 143-162. Diakses 22

Februari 2019. https://hrcak.srce.hr/215545.

Croteau, David A. Perspectives On Tithing Four Views. Nashville, Tanesse: B\&H

Publishing, 2011.

Darmaputera, Eka. Imamat Yang Sempurna: Pemahaman Surat Ibrani Tentang Iman Dan Keimaman Yesus. Jakarta: BPK Gunung Mulia, 2012.

Daymon, Christine, dan Immy Holloway. Metode-Metode Riset Kualitatif Dalam Public Relation Dan Merketing Communication. Yogyakarta: Bentang Pustaka, 2008.

Dwitanto, Ardo Ryan. "Perpuluhan: Awal Pengelolaan Keuangan Pribadi Manajemen Kita." Tabloid Reformata Edisi 111, tahun VII (2009): 1-31. Diakses 22 Februari 2019.

https://books.google.co.id/books?id=E_ejBwAAQBAJ\&pg=PA14\&source=gbs_to c_r\&cad $=3 \# \mathrm{v}=$ onepage $\& \mathrm{q} \& \mathrm{f}=$ false.

Guthrie, D., J. A. Motyer, A. M. Stibbs, and D. J. Wiseman Obe. Tafsiran Alkitab Masa

Kini 3 Matius-Wahyu. Vol. 3. Jakarta: Yayasan Komunikasi Bina Kasih, 2014.

Grolier Academic Encyclopedia Vol. 19. New Delhi: Arete Publishing Company, 1983. Haag, Herbert. Kamus Alkitab. Flores: Nusa Indah, 1989. 
Hasmawaty. "Kemampuan Menyimak Anak Melalui Kegiatan Bercerita (Studi Kasus Pada Taman Penitipan Anak Athirah Makassar)." Jurnal Ilmu Teologi dan Pendidikan Agama Kristen 1, no. 1 (Juni 2020): 55-68.

https://ojs.sttjaffray.ac.id/jitpk/article/view/463.

Henry, Matthew. Tafsiran Matthew Henry Injil Matius 15-28. Surabaya: Momentum, 2008.

—. Tafsiran Matthew Henry Kitab Kejadian. Surabaya: Momentum, 2014.

Herlianto. Teologi Sukses Antara Allah Dan Mammon. Jakarta: BPK Gunung Mulia, 2009.

Hill, Andrew E., dan John H. Walton. Survei Perjanjian Lama. Malang: Gandum Mas, 2013.

Hutabarat, Samuel. Memuliakan Tuhan Dengan Harta: Mengelola Berkat Financial Sesuai Standar Firman Tuhan. Yogyakarta: ANDI, 2014.

Jaffray, R. A. Tafsir Kitab Bilangan. Makassar: Kalam Hidoep, sa.

Kee, Howard Clark. Alkitab Edisi Studi. Jakarta: Lembaga Alkitab Indonesia, 2014.

Kioulachoglou, Anastasios. Tithing, Giving And The New Testament. Orlando: Xulon Press, 2008.

McMaken, W. Travis. "Reading Scripture with John Calvin: Malachi” (2016): 1-31. Diakses 1 April 2019.

https://www.academia.edu/23241728/Reading_Scripture_with_John_Calvin__Malachi?auto=download.

Milss, Dag Heward. Mengapa Orang-orang Kristen Yang Tidak Mengembalikan Perpuluhan Menjadi Miskin Dan Bagaimana Orang-Orang Kristen Yang Mengembalikan Perpuluhan Menjadi Kaya. London: Parchment House, 2015.

Morris, Leon. Injil Matius. Surabaya: Momentum, 2016.

Munthe, A. Tema-Tema Perjanjian Baru. Jakarta: BPK Gunung Mulia, 2009.

Murray, Stuart. Beyond Tithing. Eugene, Oregon: Wipf and Stock Publishers, 2012.

Naharto, Michelle Jane. "Analisis Tujuan Pemungutan Serta Pengertian Penghasilan Menurut Perpajakan Dan Persepuluhan Bagi Wajib Pajak Orang Pribadi." Accounting Review 4, no. 1 (2014): 1-14.

Newman Jr, Barclay M. Kamus Yunani-Indonesia. Jakarta: BPK Gunung Mulia, 1991.

Objantoro, Enggar. "Augustine's Theological Method And Contribution to the Christian

Theology." International Journal of Indonesian Philofophy \& Theology 1, no. 1 (Juni 2020): 56-63. https://doi.org/10.47043/ijipth.v1i1.2.

Pandiangan, Benry, dan Stimson Hutagalung. “Analisis Pemahaman Anggota Jemaat Pakusarakan Tentang Mengembalikan Persembahan Persepuluhan Ke Rumah Perbendaharaan Tuhan Menurut Maleakhi 3:10.” Jurnal Marturia 1, no. 1 (1 Juli 2017): 111-141.

Patty, Agustina Christina, dan Gugus Irianto. “Akuntabilitas Perpuluhan Gereja.” Jurnal Akuntansi Multiparadigma 4, no. 2 (2013): 177-187.

Pfeiffer, Charles F., dan Everett F. Harrison. The Wycliffe Bible Commentary Vol. 1. Malang: Gandum Mas, 2014.

Quiggle, James D. Why Christians Should Not Tithe: A History of Tithing and a Biblical Paradigm For Christian Giving. Eugene, Oregon: Wipf and Stock Publishers, 2009.

Rantesalu, Marsi Bombongan. "Karakter Kejujuran dalam Gereja Masa Kini." Jurnal Ilmu Teologi dan Pendidikan Agama Kristen 1, no. 1 (Juni 2020): 43-54.

https://ojs.sttjaffray.ac.id/jitpk/article/view/475.

Rifai. Superioritas Kristus Dalam Kitab Ibrani. Sukoharjo: BornWin’s Publishing, 2019. 
Rodriguez, Angel Manuel. "Tithing In The Writings Of Ellen G. White" (Associate

Director Biblical Research Institute General Conference, 2001): 1-36.

Ronda, Daniel. Pengantar Konseling Pastoral. Bandung: Kalam Hidup, 2015.

Rowley, H. H. Ibadat Israel Kuno. Jakarta: BPK Gunung Mulia, 2004.

Sabdono, Erastus. Perpuluhan. Jakarta: Rehobot Literature, 2018.

Selan, Ruth F. Menggali Keuangan Gereja. Bandung: Yayasan Kalam Hidup, 1999.

Sinulingga, Risnawaty. Tafsiran Alkitab: Kitab Amsal 1-9. Jakarta: BPK Gunung Mulia, 2007.

Sirait, Bigman. Tersesat Di Gereja Apa Iya Bisa? Jakarta: Yayasan Pelayanan Media Antiokhia (YAPAMA), 2017.

Sitanggang, Murni H. “Teologi Biblika mengenai Perpuluhan.” Veritas 12, no. 1 (April 2011): 19-37.

Smith, Meisha L. Joy and Truth of Tithing. Orlando: Xulon Press Christian Publishing, 2007.

Stanley, Wasidi Sugianto, Tantra Lingga Weinardy, Christian Eliazar Bawias, and Andre Yulius. "Pengaruh Persepuluhan Terhadap Pertumbuhan Kesejahteraan Jemaat Di Gereja Bethany Indonesia 'Almasih Qom' Surabaya.” Journal Kerusso 3, no. 1 (28 Maret 2018): 19-23.

Sukwiaty, Sudirman Jamal, dan Slamet Sukamto. Ekonomi SMA Kelas XII. Jakarta: Yudhistira, 2009.

Tandiassa. S. Buah Terlarang. Yogyakarta: Lumela, 2018.

Tedja, Tjandra. Persepuluhan, Masih Relevankah? Menyingkap Kebenaran Yang Disembunyikan. Jakarta: Living Water Publishing, 2015.

Teo, Steven. Persepuluhan Kunci Kebebasan Finansial: Menguji Tuhan Dengan 10\% Income Kita. Yogyakarta: ANDI, 2013.

The Encyclopedia Britannica Vol. 22. London: The Encyclopedia Britannica Company. LTD, 1989.

The Internasional Standard Bible Encyclopedia. Grand Rapids: Wm. B. Eerdmans Publishing Co, 1955.

The Word Book Encyclopedia. Chicago: Word Book, Inc., 1992.

Widyatmadja, Josef P. Yesus Dan Wong Cilik. Jakarta: BPK Gunung Mulia, 2010.

Wijaya, Hengky. Metodologi Penelitian. Makassar: Sekolah Tinggi Theologia Jaffray, 2016.

Wommack, Andrew. Pengelolaan Keuangan. Jakarta: Light Publishing, 2013.

"Kamus Besar Bahasa Indonesia (KBBI Online).” Diakses 16 Mei 2019.

https://kbbi.kemdikbud.go.id/entri/jujur.

Libronix Digital Library System 3,0 g Copyright 2000-2007. 